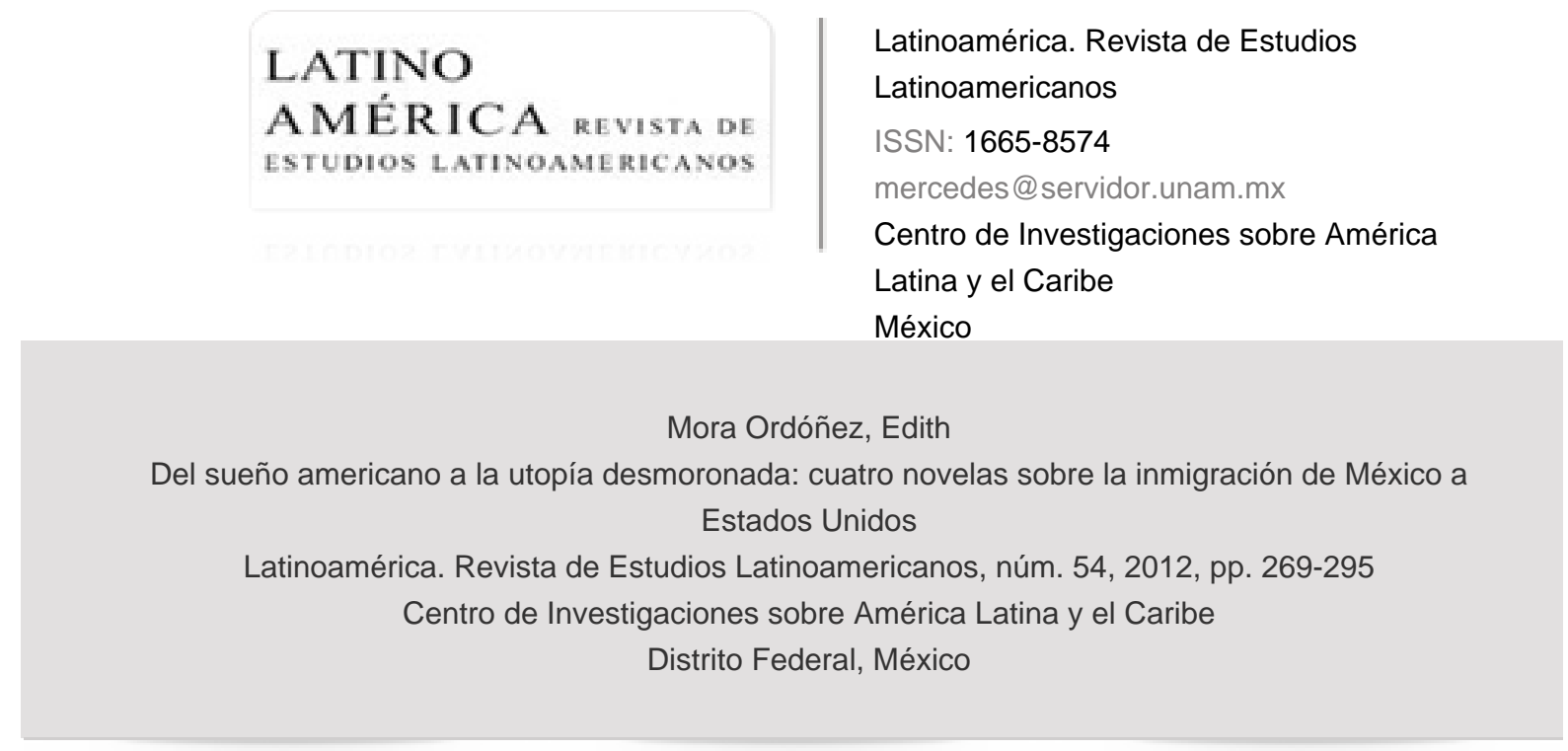

Disponible en: http://www.redalyc.org/articulo.oa?id=64023055011

Cómo citar el artículo

- Número completo

- Más información del artículo

- Página de la revista en redalyc.org

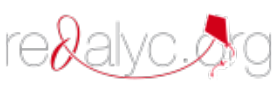

Sistema de Información Científica

Red de Revistas Científicas de América Latina, el Caribe, España y Portugal Proyecto académico sin fines de lucro, desarrollado bajo la iniciativa de acceso abierto 


\title{
Del sueño americano a la utopía desmoronada: cuatro novelas sobre la inmigración de México a Estados Unidos
}

\author{
Edith Mora Ordóñez*
}

\begin{abstract}
Resumen: El fenómeno de la inmigración hacia Estados Unidos constituye uno de los tópicos de la narrativa latinoamericana contemporánea. El espacio de las cuatro novelas de frontera, que estudiamos en este artículo desde el enfoque de los estudios culturales y de la pragmática de la comunicación literaria, dialoga con el contexto social extraliterario del viaje migratorio de los mexicanos. A través del discurso literario interpretamos el imaginario sobre la utopía prefigurada en el sueño americano, cuya cristalización es una inversión del mito: el encuentro desafortunado con otro círculo periférico donde se repite la ruina de la que partieron.

Palabras clave: Espacio, Utopía, Ruina, Inmigración, Discurso literario.

ABSTRACT: The phenomenon of the immigration towards the United States constitutes one of the common themes of the Latin-American contemporary narrative. The space in the four border novels that we study in this article, viewed from the approach of the cultural studies and the pragmatics of the literary communication, dialogues with the extraliterary social context on the migration of the Mexicans. Through the literary discourse, we realize an interpretation of the imaginarium on the prefigured Utopia of the American Dream where its crystallization inverts the myth: the unfortunate meeting with another marginal circle that repeats the same ruin from which they departed.
\end{abstract}

Key woRdS: Space, Utopia, Ruin, Immigration, Literary speech.

"Universidad de Sevilla, España (emoraordonez@gmail.com). 

narrado en los textos que motivan este estudio literario, nos encauza a la representación de los mapas imaginarios trazados a partir de un hecho trascendente compartido por la sociedad latinoamericana: el movimiento migratorio hacia Estados Unidos.

Durante las últimas dos décadas del siglo xx y la primera del presente se multiplicó la narrativa -literaria y cinematográfica-relacionada con la aventura transfronteriza de los inmigrantes que parten de diferentes países de América Latina hacia el país del norte, donde esperan encontrar el idealizado y difundido "sueño americano".

Con el propósito de reconocer las significaciones que vinculan la ficción con la realidad extraliteraria, según la interpretación de diversos autores enfocados concretamente al caso de la migración mexicana, realizamos la lectura de cuatro novelas que consideramos entablan una relación dialógica: La frontera de cristal (1995), ${ }^{1}$ de Carlos Fuentes; El corrido de Dante (2008), ${ }^{2}$ de Eduardo González Viaña; Al otro lado (2008), ${ }^{3}$ de Heriberto Yépez, y Señales que precederán al fin del mundo(2009), ${ }^{4}$ de Yuri Herrera.

Dado que nuestro propósito es interpretar claves de sentido que sustenten el imaginario colectivo sobre el espacio fronterizo mexicano-estadounidense, la selección de dichos textos obedece a una previa identificación de elementos conexos. Las tramas enfocadas en el viaje migratorio, como veremos posteriormente, entrañan discursos y simbolizaciones comunes, susceptibles de ser afrontadas mediante nociones teóricas de la semiótica

1 Carlos Fuentes, La frontera de cristal. Una novela en nueve cuentos, México, Alfaguara, 2003, 1995. [En adelante sólo se anotará LFc].

2 Eduardo González Viaña, El corrido de Dante, Murcia, Alfaqueque, 2008. [En adelante sólo se anotará LCD].

3 Heriberto Yépez, Al otro lado, México, Planeta, 2008. [En adelante sólo se anotará AOL].

4 Yuri Herrera, Señales que precederán al fin del mundo, Cáceres, Periférica, 2009. [En adelante sólo se anotará SPEM].

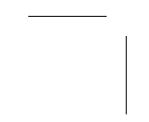


literaria. No obstante, conviene señalar que tenemos en cuenta la distancia generacional, la competencia dentro del ámbito literario y la diversidad de procedencias geográficas de los autores de las obras: Carlos Fuentes (1928), un escritor consagrado desde los años cincuenta entre la literatura mexicana e internacional; Eduardo González Viaña (1941), escritor peruano y profesor de literatura en Oregón (Estados Unidos), quien ha publicado varias novelas sobre el tema de la inmigración latinoamericana en países de habla hispana, algunas traducidas al inglés; Yuri Herrera (1970) y Heriberto Yépez (1974), ambos autores jóvenes de la literatura mexicana contemporánea, el primero nacido en el Estado de México y el segundo en Tijuana.

El contexto, la experiencia y el punto de vista ideológico de los autores son aspectos fundamentales en el análisis de las obras y penetra el conjunto de los elementos estudiados; sin embargo, en este estudio nos limitamos a presentar la interpretación de significaciones comunes sobre el espacio semiótico narrado.

Nuestro interés se ciñe a las pautas de los actuales Estudios Culturales con los cuales el texto literario reivindica su función comunicativa, dado que sus mensajes dialogan con el entorno social y con otros textos de la tradición clásica, mítica, religiosa, así como discursos actuales informativos, antropológicos, sociológicos, etcétera.

En ese sentido, reconocemos en la obra literaria un sistema abierto de signos, desde el punto de vista de la semiosfera cultural teorizada por Iuri Lotman (1996), 5 así como su condición dinámica, puesto que incorpora las voces ideológicas del autor y del lector, en los términos de Mijaíl Bajtín (1989); ${ }^{6}$ razones fundamentales, entre otras, por las cuales el discurso literario representa un fenómeno social con implicaciones prácticas.

5 Iuri Lotman, La semiosfera I. Semiótica de la cultura y del texto, selec. y trad. del ruso por Desideiro Navarro, Universitat de Valencia, Frónesis-Cátedra, 1996.

6 Mijaíl Bajtín, Teoría y estética de la novela, trad. de H. S. Kriúkova y C. Cazcarra, Madrid, Taurus, 1989. 
Dicho esto vamos a situar nuestra atención en la alusión que hacen los relatos mencionados a la cuestión del mito sobre la modernización y el progreso en Latinoamérica. Junto a sus paradojas y su derrumbamiento emerge la utopía prefigurada en el espacio norteamericano sobre el cual se construye el ideal de vida de muchos ciudadanos latinoamericanos, aquí mexicanos, que buscan salir de la pobreza.

La posmodernidad promovida en el mundo globalizado tiene otro rostro en América Latina que, por una parte, acerca los universos culturales y, por otra, polariza las condiciones sociales. Los puntos de vista relacionados con el desencantamiento del progreso reclaman que los proyectos de la modernidad no han alcanzado a todos. En lugar de la unificación a la que aspiran, agravan la desigualdad. Es por eso por lo que García Canclini llama a ésta "la globalización imaginada", "[...] porque la integración abarca a algunos países más que a otros. O porque beneficia a sectores minoritarios de esos países y para la mayoría queda como fantasía". ' Los tratados de libre comercio permitieron el acceso e intercambio económico y tecnológico para algunos, pero para la mayoría significó el aislamiento y resaltó las diferencias.

La literatura latinoamericana es un compendio de análisis y crítica de la sociedad, de promesas incumplidas, proyectos truncados y desigualdades. Los relatos sobre los desplazamientos migratorios representan la aventura mítica que comienza con una serie de motivaciones resultantes del deseo de ruptura con un entorno distópico, en el sentido de desorden y ruina, y que tiene como meta un espacio imaginado, quimérico, donde se piensa que habrá orden, armonía y bienestar.

Aunque el concepto de distopía alude a un lugar imaginario e inexistente -el futuro desastre social-lo empleamos aquí para representar un contexto físico real, el de la sociedad latinoamericana, que se opone al espacio utópico con el que revestimos, dentro del plano simbólico, el

Néstor García Canclini, La globalización imaginada, Buenos Aires, Paidós, 2002, p. 32.

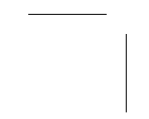


perseguido sueño americano. La escritura del género distópico, que asociamos paralelamente al modelo anti-utópico según la definición de Krishan Kumar, ${ }^{8}$ deja de ser una advertencia social presentada a través de la ficción y termina por instalarse en el siglo xx dentro del espacio real.

Desde esa perspectiva estamos considerando que el punto de partida en los relatos constituye una representación física evocadora del imaginario distópico, por lo que en correspondencia los personajes principales emprenden la búsqueda de ese paraíso, "Jardín del Edén", del cual han escuchado que existe, recreándolo en su mente en forma de lugar posible.

\section{LA "SITUACIÓN INICIAL": RUINA}

La pobreza, vista como situación de límite en la que se encuentran los personajes conscientes de las nulas oportunidades que tienen para sobrevivir económicamente, es la clave de sentido donde confluyen todas las señales de desesperanza por las cuales surge la ruptura material que implica el abandono del espacio propio y la búsqueda del imaginado.

El discurso de los narradores - siempre heterodiegéticos-, así como las voces de los personajes, coinciden en la visión del entorno social sobre el cual se enfocan los cuatro textos que analizamos.

En La frontera de Cristal, los nueve relatos conforman distintos puntos de vista de una misma historia en torno a la frontera mexicana-estadounidense, cuyo personaje central es el ambicioso Leonardo Barroso, un empresario mexicano director de fábricas maquiladoras en Ciudad Juárez, y contratista de obreros mexicanos para trabajar en ciudades norteamericanas. Junto a él, otros personajes reflejan la pluralidad de formas de vida e ideologías que se entrecruzan en el espacio fronterizo, como su

8 Véase Krishan Kumar, Utopia and Anti-Utopia in modern times, Oxford, Basil Blackwell, 1987. 
sobrina capitalina (Michelina) del Distrito Federal, quien experimenta un choque cultural en su visita al norte de México; su hermano Emiliano e hijos, frustrados por el fracaso económico; Juan Zamora, hijo de uno de sus empleados, estudiante becado en una universidad neoyorquina; Marina y sus compañeras, empleadas en una de las fábricas. También en esta novela aparecen Leandro, un conductor de taxi para turistas en México y Lisandro, un jornalero que viaja a Nueva York para trabajar en las labores de limpieza de los rascacielos.

La novela de Yépez, Al otro lado, se centra en el espacio periférico de "Ciudad de Paso", donde Tiburón, un drogadicto, hermano del propietario de una pensión habilitada para hospedar a inmigrantes que luego son guiados por "coyotes" a través de la frontera, realiza una serie de recorridos por las zonas marginales más peligrosas y decadentes de la ciudad, con la intención de encontrar una forma de subsistir económicamente antes de verse obligado a cruzar "al otro lado", como los migrantes ilegales con los que convive.

En Señales que precederán al fin del mundo el viaje fronterizo es realizado por Makina, una mujer de un pueblo en el sur de México quien, por petición de su madre, atraviesa el país hasta llegar a la frontera para encontrar a su hermano, que se ha ido hace tiempo en busca de trabajo y del cual no tienen noticias. El viaje de Makina es un guiño intertextual al recorrido mítico realizado por los muertos para llegar a Mictlán en la cosmogonía Maya.

Y en El corrido de Dante el narrador nos presenta el peregrinaje de Dante, un inmigrante mexicano, residente en Estados Unidos, que ha perdido a su hija, una adolescente que se rebela contra las normas tradicionales de su padre en medio del contexto de la cultura liberal norteamericana. El viaje de Dante pone en manifiesto la difícil travesía del mexicano, primero en su camino hacia el país del norte y luego dentro del mismo. Su experiencia revierte la percepción inicial sobre el espacio idealizado.

La travesía fronteriza comienza con la desilusión acerca del lugar de origen y constituye la primera fase del viaje iniciático señalada por Grei- 
mas: ${ }^{9}$ la "partida" o "situación inicial" de acuerdo a su modelo actancial mítico, punto desde el cual se visualiza el destino final, ese "allá" utópico.

Tiburón, en la novela de Yépez, describe el espacio fronterizo de partida como un campo desértico, indicio de un entorno característico del infierno. La sequía es un mal que se extiende alrededor de la ciudad que habita: "En Ciudad de Paso ${ }^{10}$ no crece planta que no esté bajo el cuidado de alguien. [...] El suelo no permite otra planta que no sea yerba. Esta tierra no fue hecha para alimentar nada". ${ }^{11}$

Este paisaje árido es una condición del lugar que se traslada al espacio social, donde los ciudadanos, en esos círculos periféricos que ocupan gran parte de la pretendida ciudad industrial y modernizada, experimen$\tan$ una lucha diaria por la supervivencia. El narrador de $L F C$ define bajo esta sequedad a la totalidad del país, a México. La abuela de Michelina ("La capitalina"), una aristócrata que vive a mediados del siglo xx en la capital mexicana, "asistió a la muerte paradójica de una ciudad que mientras más crecía, más disminuía, como si la ciudad de México fuese, ella misma, un pobre ser que nació, creció y, fatalmente murió". ${ }^{12}$ En la novela de Fuentes, según el caso de cada personaje, se plantea la situación "paradójica" sobre la pobreza que invade la supuesta ciudad de las oportunidades, introduciendo diferentes perspectivas y formas de denuncia social. La vergüenza y el rechazo en el discurso de los hijos de Emiliano Barroso ("La raya del olvido") reclaman al padre el infortunio del país sufrido personalmente:

¿Por qué tuviste que ser pobre y desgraciado? [... ] Eres un lastre. Si por lo menos fueras políticamente correcto. Nos avergüenzas. Un comunista. Un mexicano. Un agitador. No nos diste nada. Estabas obligado. Los padres sólo sirven para dar. En

9 A. J. Greimas, Del Sentido II. Ensayos semióticos, versión española de Esther Diamante, Madrid, Gredos, 1989, p. 167

${ }^{10}$ Ciudad de Paso es el nombre que da el autor a la ciudad fronteriza mexicana donde se desarrollan las acciones de los personajes.

${ }^{11}$ Yépez, op. cit., p. 209.

${ }^{12}$ Fuentes, op. cit., p. 15. 
cambio tú nos quitaste mucho. Nos obligaste a justificarnos, a negarte, afirmar todo lo que tú no eres para nosotros. ${ }^{13}$

El reclamo de los hijos hacia el padre alberga el reproche del ciudadano hacia su patria, que debería cumplir con su función de benefactora y que, por el contrario, ha generado necesidades, decepción y una negación justificada por parte de los ciudadanos hacia su lugar de origen.

Respecto al abandono del padre, $A O L$ cita una cuestión similar. En la frontera, señala el narrador, "[...] no sólo en el Matamorros y en Ciudad de Paso sino en todo el orbe, en todo ese mundanal en que los padres se olvidaban de los hijos, los padrastros asesinan a sus hijastros y no siempre para maltratarlos sino, peor aún, para asesinarlos y dejarlos con vida". ${ }^{14}$ Porque desde esta perspectiva no es el ciudadano el que le da la espalda a su país, sino este último el que lo despoja de sus bienes y derechos más elementales.

Por otro lado, la visión de la realidad va acompañada de sensaciones de pena y de impotencia. En las reflexiones de Lisandro (LFC en "Río Grande, Río Bravo") - un obrero mexicano que emigra a Nueva York, procedente de la clase media-baja-, se percibe el lamento de la desgracia familiar. Su padre había sido un hombre decente, entregado a su trabajo, ocupado en contribuir al progreso de su país y, sin embargo, no consiguió nunca subir en la escala económica:

Lisandro veía cadáveres, hombres asesinados, funcionarios deshonestos, intrigas sin fin, incomprensibles, luchas a muerte por el poder, el dinero, las hembras, los jotos [...]. Muerte, miseria, tragedia. En ese vértigo inexplicable había caído su padre, rindiéndose ante el caos, incapacitado para salir a luchar, trabajar. ${ }^{15}$

Esa pobreza, que además se hereda, obliga a los hijos a dejar la casa. La voz del narrador de $L F C$ es seguramente la que penetra más profunda-

${ }^{13}$ Ibid., p. 122.

${ }^{14}$ Yépez, op. cit., p. 211.

${ }^{15}$ Fuentes, op. cit., p. 212. 
mente en la crítica sobre la desigualdad social de México. El discurso es irónico y juicioso, se dirige a las instituciones, al gobierno concretamente, señalando el abuso del poder, la injusticia, la corrupción, la incompetencia de las políticas públicas.

La posición del narrador en AOL tiende a ser menos severa en la crítica, pero gana en la representación de la realidad de manera cruda, narrada tal como es en el espacio social extraliterario de la ciudad fronteriza que recrea a través de la ficción. Tiburón, en su propia franja limítrofe, aun cuando centenares de personas lo rodean sobre el eje desde el cual siempre observa: su punto de ego, reta a los transeúntes que pasan frente a él: "No se hagan, todas estas personas habían salido a la calle para encontrar a alguien que los ayudara a escapar de este país arruinado, de esta crisis económica, esta crisis total que nunca se acaba $[\ldots] "{ }^{16}$ La burla y la fatalidad son propias del lenguaje del narrador de este relato en el que todo escenario es irremediablemente decadente. Dos alternativas, puesto que esperanzas no existen aquí, dividen la elección del destino de los habitantes de Ciudad de Paso: una consiste en "volverse narco", ${ }^{17}$ otra, en irse del país para buscar el sueño americano. La primera nos desviaría a otros relatos literarios que abordan el tema del tráfico de drogas, pues también tiene su propio campo dentro de la literatura de la frontera mexicana-estadounidense; pero la segunda opción es la que motiva la trama de los textos que abordamos.

Entre el reconocimiento de la realidad - la imposibilidad de sobrevivir- y la decisión de la partida, hay una fase que define el impulso final hacia la búsqueda. Podríamos ubicarla como la franja en la que la desesperanza de los personajes revela la señal de alerta y explica a su vez el "por qué" del desplazamiento de éstos hacia el norte.

16 Yépez, op. cit., p. 87.

${ }^{17}$ Ibid., p. 67. 
"Qué frágil es la esperanza" se titula un capítulo a la mitad del texto $A O L .{ }^{18}$ El narrador expresa metafóricamente el temor que tensa a la sociedad mexicana en condiciones de pobreza, particularmente en la frontera. Enumera ejemplos que muestran la vulnerabilidad de la vida en esta región, el efecto inmediato de las acciones de los habitantes de la ciudad en el borde de la vida, siempre en una cuerda floja, entre el hambre o el peligro, en la vorágine de la violencia no sólo física, sino emocional, refiriéndose al miedo como centro oscuro donde socavan las esperanzas del que pretende moverse hacia algún lugar no contaminado por la hostilidad de la frontera.

El padre de Tiburón tenía una profesión y no fue un criminal, y "por eso se lo cargó la fregada". ${ }^{19}$ El policía, personaje de esta novela que se supone debería ser el ejemplo de hombre decente y vigilar el orden en las calles de la ciudad, termina corrompiéndose porque su salario no le propicia lo suficiente para vivir dignamente..$^{20}$

Mientras que unos tienden a la delincuencia, otros refuerzan sus valores positivos. La honradez es importante entre la sociedad mexicana de clase media o baja, como se ve en los relatos, pero está siempre vinculada con la ruina, como si el efecto directo del trabajo y el esfuerzo fuera contradictoriamente el rezago económico. A los padres de los personajes mencionados, cuya cualidad es dicho valor, falta agregar, de $L F C$, al padre de Leandro ("La apuesta") y al padre de Juan Zamora ("La pena"). Del primero sabemos la historia porque Leandro le cuenta a Encarna, su amiga española, el pasado de la familia. Mientras que el padre era mozo de un "restorán" en un hotel de Acapulco, él, siendo niño, vendía dulces en las calles. El recuerdo de Leandro lo entristece, pues tiene la imagen de su padre vestido con el uniforme, la servilleta en el brazo y la cabeza siempre inclinada hacia el suelo: "[...] era agachado, sumiso, esclavo, como

${ }^{18}$ Ibid., p. 180.

${ }^{19}$ Ibid., p. 33.

${ }^{20}$ Ibid., p. 93. 
casi todos en este país, unos lo pueden todo, muy poquitos, la mayoría están jodidos para siempre, no pueden nada. Unos cuantos chingones esclavizan a una bola de agachados. Así ha sido siempre". ${ }^{21}$

Juan Zamora conoce la forma de pensar de su padre, ya fallecido, a través de su madre indignada por la pobreza de la que nunca salieron:

-Tu padre nunca supo aprovecharse. Mira que ser durante veinte años abogado administrador de don Leonardo Barroso y morirse sin un quinto partido por la mitad. ¿En qué estaría pensando? Ni en ti ni en mí, Juanito, eso tenlo por seguro,

-¿Qué te decía, mamá?

-Que la honestidad es recompensa suficiente. Que él era un profesional honrado.22

Así, dos aspectos sobresalen a partir de esta relación padre trabajadorhonrado-ruina, y es, por una parte, el valor del trabajo, donde participan otras cualidades como la honestidad, la voluntad, la responsabilidad, sobre todo, de acuerdo a lo referido, en el caso del hombre. En el caso de las mujeres el trabajo representa una "salvación". Margarita "en el trabajo encontraba su dignidad, su personalidad, se respetaba y se hacía respetar". ${ }^{23}$ Esta visión de la vida unida al deber es un principio imprescindible para merecer el sustento diario, generalizado entre los mexicanos y más arraigado en los habitantes marginados económicamente, ubicados en los círculos de miseria.

Los textos señalan, a través de sus personajes, la desilusión, segundo aspecto de este vínculo que mencionamos. La resignación cabe después de la resistencia. Nadie quiere fallar a su casa, traicionar a su patria y a sus tradiciones. En principio nadie acepta irse.

A lo largo de los textos percibimos en el discurso de los personajes la carga de agotamiento emocional, la preocupación y la desesperanza de

${ }^{21}$ Fuentes, op. cit., p. 235.

${ }^{22}$ Ibid., p. 43.

${ }^{23}$ Ibid., p. 270 
la que hemos hablado, momento de fragilidad donde surge la "ruptura primigenia", en palabras de Patxi Lanceros,${ }^{24}$ herida irremediable del ser en su condición fronteriza venida contra su voluntad, instante de crisis donde surge la determinación de dejar la tierra de origen y de partir. La intención del discurso se distingue fuertemente inclinada hacia la ironía de las contradicciones sociales de México. Se introduce el reproche de los personajes en sus circunstancias de límite, comunes en el contexto fronterizo. La opinión de la polarización de la riqueza se encuentra visible en la mayoría de los relatos: " [...] Se acabó la lana, llegó la crisis, entambaron al empresario, al funcionario, al mero mero, y ni así se acaba la corrupción, jodido país, chingado país, desesperado país, como una rata sobre una noria, haciéndose la ilusión de que camina pero nunca cambia de lugar", ${ }^{5}$ reniega Margarita porque nada había obtenido a pesar de haber dejado su pueblo para irse a trabajar a la frontera.

\section{"ME VOY PARA ALLÁ, ME VOY AL NORTE"}

Después de la conciencia sobre la espiral de la pobreza viene ese momento de "crisis y ruptura", de "decisión", que Bajtín define como "cronotopo del umbral": la partida. ${ }^{26}$

Los desplazamientos de los personajes que emigran siguen siempre la dirección hacia el norte, esto es, de las provincias del centro y sur de México hacia las capitales fronterizas mexicanas y posteriormente de éstas a Estados Unidos.

Una serie de factores ayudan al personaje a convencerse de que la mejor opción, antes que ser narco, es emigrar al norte. La primera fase de la búsqueda se halla en la "modalidad del querer", señalada por Greimas, ${ }^{27}$

${ }^{24}$ Patxi Lanceros, La herida trágica: el pensamiento simbólico tras Holdërlin, Nietzsche, Goya y Rilke, Barcelona, Anthropos, 1997, p. 17.

${ }_{25}$ Fuentes, op. cit., p. 272.

${ }^{26}$ Bajtín, op. cit., p. 399.

${ }^{27}$ Greimas, op. cit., p. 167. 
como la manifestación del deseo del viaje. Ahora, la desesperanza funciona como una revelación que anima a la formulación de expectativas, a la construcción del sueño de muchos, el sueño americano. La "idea" de encontrarse en Estados Unidos se convierte en una necesidad imperiosa y una meta que impulsa la búsqueda. Visualizar la utopía tiene una función elemental para dar certidumbre a la decisión, pues el personaje, como hemos dicho antes, tiene que asimilar que es la única alternativa, aunque tenga que ir en contra de sus valores de unidad familiar y de lealtad a la tierra de origen: "Sus miradas reflejaban un espíritu cuya primera mitad era la esperanza de llegar pronto al país de los sueños y de las oportunidades, y la otra mitad, era una tristeza de abarcar hasta tres mitades del alma". ${ }^{28}$

Tiburón, que despreciaba a los inmigrantes avergonzados por su condición, opta finalmente por irse de Ciudad de Paso y cruzar a Sunny City: "La idea de vivir allá, conocer otro mundo, lo hacía feliz. Tenía que salir de su ciudad, aunque eso significara dejar el dinero fácil. Ya encontraría algo en la Unión. Allá siempre hay algo esperado"..$^{29}$ Así comienza la hazaña de los que viajan al otro lado, con un viaje imaginario, habiendo dado forma a la utopía.

Los valores del espacio sagrado, tal como señala Mircea Eliade, el lugar "cosmizado" - que los personajes reconocen como "su mundo" habitado y bien organizado-, se invierten tomando la forma del caos, una región "desértica y desconocida". ${ }^{\circ 0}$ En este caso es desconocida por efecto del rechazo, del exilio experimentado por el sujeto al verse abandonado por su progenitor, llámese padre o patria, partiendo de los hechos citados.

Allá, del otro lado, se encuentra idealizado el nuevo "centro" que será cosmizado. Mientras tanto, "el camino es [... ] un rito del paso de lo pro-

${ }^{28}$ González Viaña, op. cit., p. 75

${ }^{29}$ Yépez, op. cit., p. 163.

${ }^{30}$ Mircea Eliade, Lo sagrado y lo profano, Barcelona, Paidós Orientalia, 1999, p. 36. 
fano a lo sagrado; de lo efímero y lo ilusorio a la realidad y la eternidad; de la muerte a la vida, del hombre a la divinidad". ${ }^{1}$

La fragmentación del ideal social se percibe en la expresión de personajes procedentes de espacios diferentes dentro de la frontera. El "debe ser" - explicado por Buber ${ }^{32}$ es para el empresario Leonardo Barroso ("Malintzin de las maquilas") la labor a favor del progreso cristalizado en la obra urbana mediante la instalación de fábricas ensambladoras; es "la satisfacción del deber cumplido". Ese orgullo contrasta con la percepción de los marginados, quienes consideran que no se les ha atendido ni en la cuestión más elemental, que radica en asegurar las condiciones necesarias para vivir. Estas "variaciones imaginativas" de la utopía, extraídas del tejido ideológico de los grupos sociales, promueven la búsqueda del progreso pero a través de caminos distintos, unos mediante el ejercicio del poder, otros mediante la única opción puesta en el exilio. Pues la utopía, citando lo dicho por Ricoeur, es ideológica en ese sentido. ${ }^{33}$

"Si creces en la frontera tienes que escoger: de este lado o del otro. Nosotros escogimos el Norte", ${ }^{4}$ dicen los hijos a Emiliano Barroso ("La raya del olvido"), que de niños no tuvieron la vida que esperaban y optaron por emigrar a Estados Unidos abandonando a su padre.

Si en su ensayo sobre la utopía Alfonso Reyes señala que el escritor se adelanta al jurista cuando imagina y crea en lo novelesco espacios que reflejan una sociedad perfeccionada, ${ }^{35}$ en la literatura de la frontera se presenta un proceso contrario, pues el escritor da testimonio de una uto-

${ }^{31}$ Mircea Eliade, El mito del eterno retorno, Madrid, Alianza Editorial, 2004, p. 26.

${ }^{32}$ La imagen utópica es un cuadro de lo que "debe ser", lo que el autor de ella desearía que fuese real $[. .$.$] . Va unido a algo sobrepersonal que se comunica con el alma, pero que no está con-$ dicionado por ella. Lo que en él impera es el afán por lo justo, que se experimenta en visión religiosa, o filosófica, a modo de revelación o idea, y que por su esencia no puede realizarse en el individuo, sino sólo en la comunidad humana, en Martin Buber, Caminos de utopía, México, FCE, 1992, p. 17.

${ }_{33}$ Paul Ricoeur, Ideología y utopía, Barcelona, Gedisa, 1994, p. 59.

${ }_{34}$ Fuentes, op. cit., p. 123.

35 Alfonso Reyes, Obras completas, t. XI. No hay tal lugar, México, FCE, 1960, p. 338. 
pía ya elaborada en la realidad extraliteraria, aprehendida en las ilusiones de los inmigrantes mexicanos y materializada en la ciudad estadounidense. De hecho, la idealización sobre el sueño americano se ha extendido tanto que emigrar se convierte en un proyecto común en los pueblos provincianos de México. Incluso, en algunas poblaciones, la inmigración llega a instituirse como una práctica cotidiana, y podría decirse, un ejemplo a seguir. Es en muchos casos la única forma de mantener económicamente al pueblo: "El pueblo de Benito Ayala vivía de enviar trabajadores a los Estados Unidos y de las remesas que los trabajadores hacían al pueblo"; ${ }^{36}$ no sólo las familias se adaptan a esta forma de ingreso, sino que también se benefician hospitales, escuelas, iglesias, ayuntamiento, todos.

Dicho por Beatriz en $E C D$, emigrar al otro lado era un designio: "Dios nos ha condenado desde antes de nacer a caminar como topos libando tristeza y agua sucia mientras avanzamos hacia el norte". ${ }^{37}$ En palabras de Dante, "[...] es que en mi tierra ya no somos hombres. Creo que nos hemos comenzado a convertir en peces. Te lo digo porque apenas nacemos ya estamos camino al norte". 38

En ese sentido, la voz de los personajes se vuelve un elemento fundamental en la comprensión de la lucha y la tenacidad durante el trayecto y después de éste cuando consiguen estar en el lado estadounidense. En cada relato, el discurso de los personajes es una sentencia que determina la transfiguración de su sueño utópico.

Sabemos hasta aquí "por qué" se van los personajes. Distinto es conocer qué quieren encontrar del otro lado, "para qué" realizan el viaje, cómo se justifican ante la sociedad que abandonan. En el caso de Dante, éste se despide de Beatriz con una promesa: "fue al cumplir los 21 años cuando le dijo que se iba a pasar al norte, y que allí trabajaría duro hasta tener dinero suficiente para pedirle que fuera a acompañarlo y formaran

${ }^{36}$ Fuentes, op. cit., 257.

${ }^{37}$ González Viaña, op. cit., p. 186.

${ }^{38} \mathrm{Ibid}$., p. 75. 
una familia" ${ }^{39}$ El discurso se repite en la mayoría de los jóvenes migrantes que se despiden de sus familias, con la seguridad de que encontrarán la fortuna y la promesa de que volverán para "sacar" al resto de la miseria. Así, en $L F C$, Serafín Romero, "El Mierdas", un adolescente que nació y creció en la inmundicia de la periferia mexicana, inicia el trayecto al norte:

A los veinte años, Serafín Romero agarró para el Norte, le dijo a su gente sálganse de aquí, este país no tiene remedio, el PRI es la razón de sobra para largarse de México, yo les juro que veré la manera de ayudarlos en el Norte, tengo unos parientes en Juárez, tendrán noticias mías, chavos $[\ldots] .^{40}$

Ir al "Norte", ese es por lo pronto el nombre que los personajes dan a la utopía cuando se encuentran todavía preparando el viaje. El norte de México es una región que -aunque desértica- posee otro tipo de riqueza debido a la actividad del campo impulsada por los terratenientes desde la época de la Revolución de 1910, y por su cercanía con Estados Unidos, que invierte y genera empleos en la frontera mexicana a través de las maquiladoras. Por eso el norte es el primer destino; enseguida los más obstinados hablarán de irse al otro lado, a Estados Unidos.

A propósito, notamos la constante repetición del indicativo "allá" en los cuatro relatos y su profunda significación en cuanto a semantización deíctica. El norte es, en el plano espacial de las significaciones, un "allá" imaginado como el paraíso donde se puede hallar trabajo y "recomenzar la vida". ${ }^{41}$ Es, además, un sueño que aparentemente se vuelve realidad, según relatan los inmigrantes que se van y vuelven mostrando el dinero obtenido.

Al hermano de Makina lo convenció un conocido de su padre, ya desaparecido, de que "tenían un terrenito allá" ${ }^{42}$ Sin averiguar antes acerca de esa información, el hermano prefiere creer y aferrarse a ese sueño

${ }^{39}$ Ibid., p. 61.

${ }^{40}$ Fuentes, op. cit., p. 277.

${ }^{41}$ Ibid., p. 166.

${ }^{42}$ Herrera, op. cit., p. 31. 
infundado, excusa para irse de inmediato al otro lado: "Me voy a reclamar lo nuestro". Aun cuando no es un objetivo en ninguno de los casos de los inmigrantes, el narrador de este relato, como ocurre también en la novela de Fuentes, alude a la recuperación silenciosa del territorio mexicano perdido en el siglo XIX.

De los diálogos revisados hasta aquí podemos destacar, entre otras claves de sentido, la unidad de los mensajes enunciados por el narrador y por los personajes entre las novelas, principalmente aquellos que surgen de los grupos sociales marginados en las ciudades fronterizas. Dicha coincidencia refleja una voz y una significación literaria cohesionada, pero también, desde la relación dialógica de los textos con el contexto al que se refieren, dichos mensajes nos ponen frente a hechos y significados sociales importantes que nos revelan una parte de la concepción de la realidad, y de las ideologías en la región fronteriza mexicana-estadounidense.

\section{UN EDÉN PERIFÉRICO}

Después de una serie de pruebas e intentos fallidos el héroe cruza la línea fronteriza y cree haber llegado a su destino. Esta victoria aparente va volviéndose turbia a medida que se adentra en el territorio estadounidense.

En los textos literarios que nos ocupan vemos desmoronarse el llamado sueño americano cuando los personajes creen haberlo alcanzado.

Las primeras imágenes recibidas por el inmigrante cristalizan el paisaje idílico que figuraba en su imaginación antes y durante el viaje. A primera vista, la ciudad que ve es justamente el sueño realizado, una "heterotopía", el espacio "absolutamente otro"/3 —empleando el concepto

${ }^{43}$ Del texto Des espaces autres a partir de las conferencias radiofónicas emitidas por el autor en 1966 en France-Culture, publicadas desde entonces en varias revistas, incluyendo Fractal, octubre-diciembre, 2008, la cual consultamos para el presente trabajo. El concepto de "heterotopías" según la definición de Foucault se refiere a "esos espacios absolutamente otros" reservados por las sociedades para fines específicos, algunos sagrados, otros prohibidos, [...] creando una ilusión que denuncia al resto de realidad como si fuera ilusión, o bien, por el con- 
de Foucault-, frente a lo cual se deja deslumbrar: "No era lo mismo mirar el polvo ardiente de México, máscara de un sol infatigable, que admirar la corona de nieve que engalanaba los muros grises y las calles negras de Nueva York, y sentir un pulso vital $\left[\ldots .{ }^{44}\right.$

El espacio narrado por el autor de esta cita, en $L F C$, dentro del relato que lleva el mismo nombre, está localizado en Nueva York, quizá la ciudad ideal, símbolo de la modernidad en el mundo. Lisandro, el personaje principal de este cuento, contempla los rascacielos, descritos como altas estructuras de cristal parecidas a palacios de nieve:

Era una ilusión. Al clarear tantito el día, podía verse un edificio todo de cristal, sin un solo material que no fuese transparente: una inmensa caja de música hecha de espejos, unida por su propio vidrio cromado, niquelado; un palacio de barajas de cristal, un juguete de laberintos azogados. ${ }^{45}$

En ese edificio piramidal y laberíntico, donde trabaja Lisandro y sus compañeros mexicanos, el narrador continúa describiendo - y evocando a la biblioteca del monasterio en El nombre de la rosa, de Umberto Eco (1980)-, que todas las oficinas de cristal se situaban en torno a un atrio central con seis costados de los cuales caían seis muros como acantilados, desde donde se podían ver, ahora, como en el aleph borgiano, todos los ángulos y a todos los empleados a través de las ventanas transparentes. Luego, el mismo personaje, subiendo por el ascensor para llegar a la cima, experimenta la sensación de estar avanzando hacia el lado contrario, "descendiendo a un extraño mar de vidrio en un mundo desconocido, patas arriba". ${ }^{46}$

Este fragmento que apunta hacia el caos de lo aparentemente idílico nos anuncia, como veremos en otras citas, el resquebrajamiento de la utopía. De acuerdo a la posición del sujeto, la fantasía del sueño alojado

trario, creando realmente otro espacio real tan perfecto, meticuloso y arreglado cuanto el nuestro está desordenado, mal dispuesto y confuso".

${ }^{44}$ Fuentes, op. cit., p. 212.

${ }^{45}$ Ibid., p. 213.

${ }^{46}$ Loc. cit. 
en el "norte" puede o no continuar sosteniéndose. Se mantiene en las maquiladoras en un principio, a pesar de las condiciones adversas a las que se enfrentan las empleadas. Aunque las fábricas a las que se refieren los textos analizados están ubicadas en el lado mexicano, constituyen una parte del norte idealizado, el destino para las mujeres que emigran desde los pueblos del sur, una especie de mundo artificial manipulado para crear un ambiente moderno de producción y bienestar que nos hace pensar en uno de los primeros referentes distópicos literarios: Un mundo feliz, de Aldous Huxley:

[...] la fábrica montadora de televisores a color, un espejismo de vidrio y acero brillante, como una burbuja de aire cristalino, era como trabajar rodeadas de pureza, de brillo, casi de fantasía, tan limpia y moderna la fábrica [... ].

-Es tan bonito este lugar -suspiró Marina, evitando pisar con sus zapatos de stileto los prados verdes con la advertencia doble: no pise el paso/keep off the grass.

-Si hasta parece Disneylandia - dijo Dinorah entre seria y risueña. ${ }^{47}$

En estas referencias aparece, coincidiendo con la cita anterior, la percepción de los cristales como parte del paisaje de la ciudad moderna idealizada. Los cristales, en su significado simbólico, "dispensan la facultad de elevarse al cielo"; ${ }^{8}$ están por lo tanto relacionados con el movimiento de ascenso, y su transparencia con la pureza y la unión de los contrarios, puesto que esto permite ver a través de ellos.

Por otra parte, la empleada compara el entorno de la maquila con Disneylandia ${ }^{49}$ el espacio artificial inspirado en un mundo ideal, creado a partir de escenarios y seres de fantasía. Por encima del caos la ciudad no

${ }^{47}$ Ibid., pp. 144-146.

${ }^{48}$ Jean Chevalier y Alain Gheerbrant, Diccionario de los símbolos, Barcelona, Herder, 2007, p. 357.

${ }^{49} \mathrm{Al}$ respecto de la "hiperrealidad" Baudrillard introduce, para ejemplificar, el modelo "Disneylandia", simulacro que representa un universo perfecto. Pensado como espacio imaginario, finalmente su efecto opera en sentido contrario, pues "Disneylandia es presentada como imaginaria con la finalidad de hacer creer que el resto es real, mientras que cuanto lo rodea Los Ángeles, América entera, no es ya real, sino perteneciente al orden de lo hiperreal y de la simulación", en Jean Baudrillard, De la seducción, Madrid, Cátedra, 1998, p. 30. 
deja de ser un ideal, es una jungla que seduce a través de una idea de realidad creada a partir de una entidad fantasmagórica. Es, siguiendo a Baudrillard: "una representación instantánea y exacerbada: la del sexo en estado puro". ${ }^{50}$

La llegada de Makina al lado estadounidense (SPFM) es descrita por el narrador como una cima, desde la cual observa caer la nieve, "una lluvia de cristales":

[... parecía una suma de cruces o el plano de un palacio, en cualquier caso un prodigio sólido y elaborado, y cuando se disolvió unos instantes después se preguntó cómo es que algunas cosas del mundo, algunos países, algunas personas, podían parecer eternas si todo era como ese diminuto palacio de hielo: irrepetible y precioso y frágil..$^{51}$

Lo cierto es que al final ese palacio se convierte en un espejismo o, quizá, dicho de otra forma, una barrera impenetrable. Los inmigrantes se ven obligados a permanecer al margen de esa imagen soñada, puesto que no están llamados a pertenecer a ella. Su lugar está en las orillas, en lo que constituye la periferia estadounidense.

El efecto, por lo tanto, es contrario al esperado. El lugar que se suponía sería el paraíso anhelado se convierte finalmente en otro círculo de miseria, pues mientras que los inmigrantes intentan adaptarse a las condiciones de vida norteamericana, tienen que conformarse con las escasas oportunidades de trabajo que se les conceden. En los relatos analizados es verdad que tienen un mejor trabajo que en sus pueblos de origen en México, sin embargo, se refleja la imposibilidad de integrarse al estilo de vida de los ciudadanos estadounidenses y el temor de caminar por las calles, puesto que son vistos como extraños o delincuentes.

Los inmigrantes terminan aislándose en barrios donde repiten su historia de pobreza. Las significaciones en torno al espacio decadente re-

${ }^{50}$ Ibid., p. 34 .

${ }^{51}$ Herrera, op. cit., p. 63. 
chazado y el espacio añorado se invierten, como señala Tiburón (AOL): "[...] lo que nadie parece saber es que cuando todos estemos del otro lado de la frontera, cuando ya todos nosotros nos hayamos mudado al norte de la línea internacional, también vamos a echar a perder ese país, también a ese lo vamos a hundir". ${ }^{2} Y$ es entonces que desean volver al paraíso ubicado en el lugar de origen.

En ese caso la huida carece de sentido; la utopía confirma su principio: "no hay tal lugar", ${ }^{33}$ no existe. Incluso sin necesidad de volver, los inmigrantes instalados en ese espacio creado por y para ellos, ya se encuentran en el sitio de partida, devorados por el "eterno retorno", nunca pueden abandonar el inframundo.

Dante $(E C D)$ vive desde hace muchos años en Estados Unidos, y sin embargo no deja de sentirse solo: "La verdad es que todos estamos en lo mismo. Desde que salí de mi tierra, desde que vine a estos rumbos, no he dejado de sentirme como encerrado, como si no tuviera forma de salir". ${ }^{44}$ Al final, el héroe ha dejado una prisión, ha vencido todos los obstáculos para entrar en otra jaula que tiene una gran ventana de cristal con vistas al paraíso.

El norte, asociado en este contexto con la riqueza, tiene simbólicamente connotaciones contrarias: es el "país del frío, del hambre, de la noche y de la aridez".55 No olvidemos que en la cosmogonía náhuatl es el lugar donde residen los muertos. Mictlán se sitúa en el norte. ${ }^{56}$ En el libro de Jeremías, del texto bíblico cristiano, se dice que en el norte reina la

52 Yépez, op. cit., p. 24.

${ }^{53}$ La Utopía de Tomás Moro, escrita en 1516, inauguró el término que se instauró como género literario y su perspectiva no tiene vinculación con la ideología, sino que se refiere a la creación de "ningún lugar", que es la definición etimológica de utopía. En el relato, Utopía es el nombre de una isla que no existe, y su nombre significa "no hay tal lugar", en Ricoeur, op. cit., p. 57.

${ }^{54}$ González Viaña, op. cit., p. 43

${ }_{55}$ Chevalier y Gheerbrant, op. cit., p. 860.

${ }^{56}$ También, desde la perspectiva simbólica, "según el libro Babir, el mal reside en el norte y Satán, en cuanto principio de seducción, principio del mal, viene del norte. El norte es el lugar del infortunio. [...] El viento del norte se considera devastador", en ibid., p. 756. 
maldad. Por lo tanto, la interpretación de la condición del inmigrante que se impacta con la desventura del norte tiene como partida estas premisas del imaginario clásico, que no se hallan tan difundidas en el entorno cultural al que nos referimos.

El desencuentro con el norte parece una revelación que muchos, o la mayoría, prefieren pasar por alto. Es mejor negarlo y continuar con el viaje iniciado. Excepto para Tiburón, esta realidad es ya conocida, no se engaña y no se detiene para decir que Los Ángeles (California) "está lleno de cochinero: inmigrados". ${ }^{57}$

Por otra parte, Makina percibe la presencia de sus compatriotas al caminar por la ciudad estadounidense. Los ve ocultar la mirada intentando pasar desapercibidos para no hacer notar su identidad. Pese a ello el personaje los distingue:

Era el paisanaje armado de chambas: albañiles, vendedores de flores, estibadores, choferes, depurando el disimulo para no delatar ningún propósito común sino nomás, nomás, nomás: que estaban allí para recibir órdenes. Eran como allá, pero menos chifladores, y ninguno pordioseraba. ${ }^{58}$

Aunque el "paisanaje" es consciente del nuevo espacio de ruina en el que se introduce, no vemos en los relatos que ninguno de ellos se atreva a reconocerlo frente a los otros, ni aun entre sus iguales. En su labor diaria el inmigrante intenta crear un ambiente cómodo para convencerse a sí mismo de que es mejor que aquel abandonado. Mientras trabaja intenta no mirar a su alrededor para evitar contaminarse de la miseria, y, como advierte Makina, hace menos ruido del que acostumbra en su lugar de origen - reprimiendo al mexicano alegre y jocoso-. Muestra una actitud más arrogante para esconder su pena. Cuando vuelve a su pueblo finge que en el otro lado vive el sueño por el cual se fue y presume lo que ha ganado hasta entonces con su trabajo: un coche, un teléfono, ropa nueva, dólares en el bolsillo.

57 Yépez, op. cit., p. 138.

${ }^{58}$ Herrera, op. cit., p. 65. 
La vOz de Tiburón (AOL) en su posición observadora y casi siempre irónica, aguda, revela en el relato otra de las verdades pocas veces dichas sobre el desencanto del sueño americano:

\begin{abstract}
¿Irse al Norte? Ir cada vez más al Norte, cosa seria, cosa que hay que pensar, porque las consecuencias de nortearse son graves, definitorias, jodidas, nada más miren a los inmigrados, lo que les pasa a los paisanos cuando van al otro lado, trabajan allá de criadas, jardineros, limpiabotas, barrenderos, meseros, achichincles de los americanos y regresan hechos una cagada. Los inmigrados se sienten superiores porque tienen más dinero que los que no han migrado, pero están arruinados..$^{59}$
\end{abstract}

El escenario de la condición periférica, que se repite en el espacio estadounidense representado en los textos que referimos, dialoga intertextualmente con textos fílmicos producidos que ya desde décadas anteriores ahondaron en esta temática social fronteriza. Un ejemplo, específicamente sobre la desilusión del mexicano que vive la experiencia de ser inmigrante ilegal en Estados Unidos, la encontramos en Espaldas mojadas (1953), dirigida por Alejandro Galindo. Aquí, Rafael, arrepentido de haber ido al país del norte, donde no encontró más que desventuras, prefiere volver a su lugar de origen, pero se encuentra con dificultades al enfrentarse con los agentes aduanales. Rafael se esfuerza en hacerle comprender al oficial el desengaño que sufren los mexicanos que viven en una situación marginal: "Usted no los ha visto, viviendo siempre en los basureros de las ciudades norteamericanas" ${ }^{60}$ sacrificando su deseo de volver para encontrarse con su familia.

El destino es, por lo tanto, una espiral. Dado que "el hombre construye según un arquetipo", ${ }^{61}$ el espacio creado por el inmigrante que se instala junto a sus iguales en los límites de la frontera, tiene características similares al inframundo anterior. Esto es, si lo único verdaderamente

59 Yépez, op. cit., p. 237.

${ }^{60}$ Alejandro Galindo, Espaldas mojadas, México, ATA Films y Atlas Films, 1953, 1: 39' 13".

${ }^{61}$ Eliade, op. cit., p. 19. 
real son los arquetipos, ${ }^{62}$ y esto equivale a respetar las leyes tradicionales, entendemos que el individuo tiende por acción lógica a repetir sus esquemas de modo de vida.

Dicha concepción cíclica de la repetición de los acontecimientos parte de la idea de Nietzsche sobre el eterno retorno (La gaya ciencia, 1882), que entendemos aquí a partir de lo desarrollado por M. Eliade, desde una visión optimista de regeneración. Sin embargo, el caso que presentamos incluye la fatalidad de los mitos actuales al no tener ese carácter positivo de progreso. ${ }^{63}$ Opera en sentido contrario en la frontera norteamericana ocupada por los mexicanos, donde se cumple el determinismo de la tierra herida, infecunda, muerta.

\section{CONCLUSIONES}

La lectura de las cuatro novelas nos aporta, como hemos comprobado, diversos elementos de significación claves para la interpretación de una parte del imaginario sobre la frontera mexicana-estadounidense.

La configuración de la utopía "americana" que se resquebraja a medida que los inmigrantes sufren el desencuentro con el espacio opuesto al preconcebido en su imaginación, comunica semánticamente los textos narrativos analizados. Dicha relación interdiscursiva no es un diálogo casual puesto que comprueba la clara referencia a la realidad extraliteraria a la cual representan. A través del espacio literario dicha realidad se recrudece. Nada queda del sueño americano después del desencanto, sino

${ }^{62}$ Ibid., p. 95.

${ }^{63}$ En la teoría del eterno retorno, Eliade señala que el hombre moderno, sumido en la desesperación, acosado por un temor continuo de la historia y sus repeticiones, tiene como única salida la fe, pues la presuposición de la existencia de Dios es la vía de la libertad. Así, concluye: "[...] el cristianismo se afirma sin discusión como la religión del 'hombre caído en desgracia': y ello en la medida en que el hombre moderno está irremediablemente integrado a la bistoria y al progreso, y en que la historia y el progreso son caídas que implican el abandono definitivo del paraíso de los arquetipos y de la repetición", en Eliade, op. cit., p. 156. 
la reconstrucción del lugar anhelado: un impulso de continuar la búsqueda, la invención de otro paraíso o el retorno al lugar de origen.

Después de todo, según las ideas veladas por los autores, nada en la sociedad de la modernidad, de la modernización y de las promesas multiculturales, es lo que parece, sino simulacro y mito.

La paradoja domina el extenso relato de los movimientos migratorios en el contexto real y en la ficción. Los personajes dejan la miseria buscando un sueño dentro de lo que es finalmente otra periferia más decadente. "Lo de fuera y lo de dentro son, los dos, íntimos; están prontos a invertirse, a trocar su hostilidad. Si hay una superficie límite entre tal adentro y tal afuera, dicha superficie es dolorosa, en ambos lados" ${ }^{64}$ Por lo tanto, la perspectiva del espacio fronterizo, desde la posición del inmigrante, ha dado un giro. Lo que antes era el infierno es ahora paraíso.

En ese sentido, además, vemos incorporada la estética contemporánea invertida que señala el rompimiento del orden clásico, en función de la libertad con que se expresa el espacio cultural, como puntualiza, entre otros, Omar Calabrese, ${ }^{65}$ dentro de un estilo "neobarroco" que explica esa organización asimétrica del espacio. En el mismo orden de ideas, la narración del espacio fronterizo, tal como lo hemos visualizado, nos encamina junto a Francisco Ayala ${ }^{66}$ a mirar la pintura de El Bosco e invertir, como él, las escenas del infierno y el paraíso, para concluir que todo ser humano nace en un mundo infernal y busca afanosamente el Edén sin llegar jamás a encontrarlo.

Recibido: 4 de noviembre, 2011. Aceptado: 23 de enero, 2012.

${ }^{64}$ Gastón Bachelard, La poética del espacio, Madrid, FCE, 1994, p. 275.

65 Omar Calabrese, La era neobarroca, Madrid, Cátedra, 1994.

${ }^{66}$ Francisco Ayala, El jardín de las delicias, Madrid, Alianza, 2006. 
EDITH MORA ORdóÑEZ

\section{BibLIOGRAFÍA}

Ayala, Francisco, El jardín de las delicias, Madrid, Alianza, 2006.

BACHELARD, GASTÓn, La poética del espacio, Madrid, FCE, 1994.

BajTín, Mijaíl, Teoría y estética de la novela, trad. de H. S. Kriúkova y C. Cazcarra, Madrid, Taurus, 1989.

BaUdrillard, Jean, De la seducción, Madrid, Cátedra, 1998.

Buber, Martin, Caminos de utopía, México, FCE, 1992.

Calabrese, Omar, La era neobarroca, Madrid, Cátedra, 1994.

Chevalier, JeAn y Alain GHEerBRANT, Diccionario de los símbolos, Barcelona, Herder, 2007.

DuRAND, GILBERT, Las estructuras antropológicas del imaginario, Madrid, FCE, 2005.

ELIADE, MirCeA, Mito y realidad, Madrid, Guadarrama, 1988. , Lo sagrado y lo profano, Barcelona, Paidós Orientalia, 1999. , El mito del eterno retorno, Madrid, Alianza Editorial, 2004.

FouCAult, Michel, Vigilar y castigar. Nacimiento de la prisión, México, Siglo XXI, 1976.

, "Des espaces autres. Hetérotopies", en Revista Fractal, núm. 51, octubre-diciembre, 2008. En www.fractal.com.mx/RevistaFractal48MichelFoucault.html.

FuENTES, CARLOS, La frontera de cristal. Una novela en nueve cuentos, México, Alfaguara, 2003.

Galindo, Alejandro, Espaldas mojadas, México, ata Films y Atlas Films, 1953.

GarCía Canclini, Néstor, La globalización imaginada, Buenos Aires, Paidós, 2002.

González Viaña, Eduardo, El corrido de Dante, Murcia, Alfaqueque ediciones, 2008.

Greimas, A. J., Del Sentido II. Ensayos semióticos, versión española de Esther Diamante, Madrid, Gredos, 1989.

Herrera, Yuri, Señales que precederán al fin del mundo, Cáceres, Periférica, 2009. 


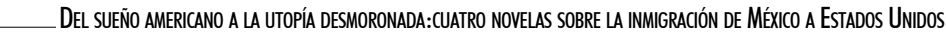

Kumar, KrISHAN, Utopia and Anti-Utopia in modern times, Oxford, Basil Blackwell, 1987.

LANCEROS, PatXi, La berida trágica: el pensamiento simbólico tras Holdërlin, Nietzsche, Goya y Rilke, Barcelona, Anthropos, 1997.

LOTMAN, IuRI, La semiosfera I. Semiótica de la cultura y del texto, selec. y trad. del ruso por Desiderio Navarro, Universitat de Valencia, Frónesis-Cátedra, 1996.

Reyes, Alfonso, Obras completas, t. XI. No hay tal lugar, México, FCE, 1960. Ricoeur, Paul, Ideología y utopía [conferencias], Barcelona, Gedisa, 1994.

Yépez, HeriberTo, Al otro lado, México, Planeta, 2008.

latino \&̇érica 54

(MÉxico 2012/1): 269-295 295 